\title{
Biological characterization and pathogenicity of a newly isolated Chinese highly virulent genotype Glla porcine epidemic diarrhea virus strain
}

\author{
Liping Zhang ${ }^{1,2} \cdot$ Xinsheng Liu $^{1,2}$. Qiaoling Zhang ${ }^{1,2} \cdot$ Peng Zhou ${ }^{1,2} \cdot$ Yuzhen Fang ${ }^{1,2} \cdot$ Zhaoliang Dong $^{1,2}$. \\ Donghong Zhao ${ }^{1,2} \cdot$ Weiyan $\mathrm{Li}^{1,2,3} \cdot$ Jiaxin Feng ${ }^{1,2} \cdot$ Yongguang Zhang ${ }^{1,2} \cdot$ Yonglu Wang ${ }^{1,2}$
}

Received: 10 November 2018 / Accepted: 10 January 2019 / Published online: 11 March 2019

(c) Springer-Verlag GmbH Austria, part of Springer Nature 2019

\begin{abstract}
Since 2010, continual outbreaks of highly virulent variants of porcine epidemic diarrhea virus (PEDV) belonging to genotype GII have led to serious economic losses for the Chinese swine industry. To better understand the biological characteristics and pathogenicity of the current prevalent Chinese PEDV field strains, in this study, a highly virulent Chinese genotype GIIa PEDV strain, CH/HBXT/2018, was isolated and serially propagated using Vero cells. Sequencing and phylogenetic analysis showed that strain $\mathrm{CH} / \mathrm{HBXT} / 2018$ contained novel insertion and deletion mutations in the $\mathrm{S}$ gene region relative to the classical strain and belonged to the genotype GIIa, similar to other recently isolated PEDV strains from China and the United States. Pig infection studies indicated that the $\mathrm{CH} / \mathrm{HBXT} / 2018$ strain was highly virulent in suckling piglets, and the median pig diarrhea dose $\left(\mathrm{PDD}_{50}\right)$ was $8.63 \log _{10} \mathrm{PDD}_{50} / 3 \mathrm{~mL}$ at 7 days postinfection (DPI). The results of the present study are important for future PEDV challenge studies and the development of new PEDV vaccines based on prevalent field strains for the prevention and control of PED in China.
\end{abstract}

\section{Introduction}

Porcine epidemic diarrhea (PED) is caused by porcine epidemic diarrhea virus (PEDV) and is a highly contagious

Handling Editor: Diego G. Diel.

Liping Zhang, Xinsheng Liu and Qiaoling Zhang contributed equally to this work.

Xinsheng Liu

liuxinsheng@caas.cn

Yongguang Zhang

zhangyongguang@caas.cn

Yonglu Wang

wangyonglumd@hotmail.com

Liping Zhang

zhanglp2319@163.com

Qiaoling Zhang

876835192@qq.com

Peng Zhou

zhoupeng02@caas.cn

Yuzhen Fang

fangyuzhen@caas.cn

Zhaoliang Dong

dzlgsdx@163.com disease characterized by watery diarrhea, dehydration, vomiting, enteritis and weight loss. PEDV infects pigs of all ages, and the mortality rate in neonatal piglets is as high

\footnotetext{
Donghong Zhao

zhaodonghong123@163.com

Weiyan Li

liweiyan160129@163.com

Jiaxin Feng

fengjiaxin0524@163.com

1 State Key Laboratory of Veterinary Etiological Biology, Key Laboratory of Animal Virology of the Ministry of Agriculture, Lanzhou Veterinary Research Institute, Chinese Academy of Agricultural Sciences, Lanzhou 730046, China

2 Jiangsu Co-innovation Center for the Prevention and Control of Important Animal Infectious Diseases and Zoonoses, Yangzhou 225009, China

3 College of Veterinary Medicine, Gansu Agricultural University, Lanzhou 730070, China
} 
as $80-100 \%[1,2]$. PED was first reported in the United Kingdom in 1971, and the causative agent CV777 strain was isolated in 1978 [3]. Through the end of the 1990s, PEDV outbreaks occurred in many European countries [4, 5]. In October 2010, a widespread outbreak of PED caused by highly virulent PEDV variants that differed from the classical European strain CV777 occurred in China and resulted in high mortality and huge economic losses. Since then, PED outbreaks have increased significantly and spread rapidly nationwide [6, 7]. PEDV variants emerged in the United States starting in May 2013 and then spread rapidly throughout the nation. Many American, Asian and European countries, including Canada, Mexico, Colombia, Japan, South Korea, the Philippines, Thailand, Germany, the Netherlands and Switzerland have also reported outbreaks of PED [6, 8-13].

PEDV is an enveloped, single-stranded, positive-sense RNA virus that belongs to the order Nidovirales, family Coronaviridae and genus Alphacoronavirus. The PEDV genome is approximately $28 \mathrm{~kb}$ in length and is composed of a 5' untranslated region (UTR), seven open reading frames (ORFs), and a $3^{\prime}$ UTR [14]. The seven ORFs encode three non-structural proteins, namely ORF1a, ORF1b and ORF3, and four structural proteins, designated receptor-binding spike glycoprotein (S), envelope protein (E), membrane glycoprotein (M) and nucleocapsid protein $(\mathrm{N})[15,16]$. ORF1a and ORF1b play vital roles in viral replication and transcription and may be related to cell adaptability and virulence [17]. The spike protein is a type I membrane glycoprotein consisting of S1 and S2 domains, which play important roles in receptor binding, cell membrane fusion, induction of host immune responses and virus neutralization by antibodies [18]. The E protein is important for viral budding, and loss of the $\mathrm{E}$ protein reduces viral virulence. The $\mathrm{M}$ protein can induce neutralizing antibodies and is the most abundant constituent of viral particles [19]. PEDV N binds to RNA, and capped $\mathrm{N}$ gene transcripts can improve replication rates during virus rescue [20].

Recently, many studies have demonstrated that commercially available PEDV vaccines derived from classical strains of PEDV cannot provide effective protection against highly virulent PEDV variant infections in China, resulting in high morbidity and mortality in neonatal piglets [21, 22]. Furthermore, almost all of the currently prevalent PEDV variants in China belong to genotype GII, particularly genotype GIIa [23]. Therefore, the development of new vaccines based on the currently prevalent PEDV variants is urgent. To achieve this objective, a current, prevalent, and highly virulent Chinese genotype GIIa PEDV strain, CH/HBXT/2018 (GenBank accession number: MH816969), was isolated, and the biological characteristics and pathogenicity of this virus strain were investigated in this study. Furthermore, the infectious titer $\left(\mathrm{PDD}_{50}\right)$ of $\mathrm{CH} / \mathrm{HBXT} / 2018$ was determined.
These results provide very helpful information for future pig challenge studies of PEDV.

\section{Materials and methods}

\section{Cells and clinical samples}

Vero cells (ATCC, CCL-81) were grown in Dulbecco's modified Eagle's medium (DMEM, Invitrogen, USA) containing $10 \%$ heat-inactivated fetal bovine serum (FBS; Invitrogen, Australia) and $1 \%$ antibiotics and antimycotics $(10,000$ units of penicillin, 10,000 $\mu \mathrm{g}$ of streptomycin, and $25 \mu \mathrm{g}$ of Fungizone ${ }^{\circledR}$ per $\left.\mathrm{mL}\right)\left(\mathrm{Gibco}^{\mathrm{TM}}\right.$, USA) and cultured at $37{ }^{\circ} \mathrm{C}$ with $5 \% \mathrm{CO}_{2}$. Fecal samples were collected from diarrheal piglets that displayed acute watery diarrhea, dehydration, and extreme emaciation in Hebei Province, China, in March 2018. These samples were confirmed to be PEDV positive by reverse transcription PCR (RT-PCR) and real-time PCR (developed in our lab). The intestinal contents were diluted tenfold in virus growth medium, which consisted of DMEM supplemented with antibiotics (100 units of penicillin and $100 \mathrm{mg}$ of streptomycin [Gibco $\left.{ }^{\mathrm{TM}}\right]$ per $\left.\mathrm{mL}\right), 0.3 \% \mathrm{TPB}$ (Sigma), and $20 \mu \mathrm{g}$ of trypsin (Gibco ${ }^{\mathrm{TM}}$, USA) per $\mathrm{mL}$, and then vortexed and centrifuged at 3,500 rpm for $30 \mathrm{~min}$ at $4{ }^{\circ} \mathrm{C}$. The supernatant was filtered through a $0.22-\mu \mathrm{m}$-poresize filter (Merck Millipore, Germany) and stored at $-70{ }^{\circ} \mathrm{C}$ for use as virus stock.

\section{Virus isolation and propagation}

Vero cells were seeded in T-25 culture flasks and placed in a $37^{\circ} \mathrm{C}$ incubator with $5 \% \mathrm{CO}_{2}$ until a $100 \%$ confluent Vero cell monolayer formed. The culture medium was then removed, and the cells were washed three times with sterile phosphate-buffered saline (PBS; pH 7.2, Gibco ${ }^{\mathrm{TM}}$, USA). Subsequently, $1 \mathrm{~mL}$ of prepared virus stock was inoculated into flasks with $20 \mu \mathrm{g}$ of trypsin (Gibco ${ }^{\mathrm{TM}}$, USA) per mL. After incubation for $1 \mathrm{~h}$ at $37^{\circ} \mathrm{C}$ with $5 \% \mathrm{CO}_{2}$, virus growth medium was added and cell culture was continued at $37^{\circ} \mathrm{C}$ and $5 \% \mathrm{CO}_{2}$, with daily observation for a cytopathic effect (CPE). When more than $90 \%$ of cells showed CPE, the supernatant and cells were harvested, frozen and thawed three times and stored at $-80{ }^{\circ} \mathrm{C}$ for the next virus passage.

\section{Tissue culture infectious dose $\left(\mathrm{TCID}_{50}\right)$ assay}

A $50 \%\left(\mathrm{TCID}_{50}\right)$ assay was used to determine the virus titer. Vero cells were seeded into 96-well plates until the wells were covered with monolayers, and tenfold serial dilutions of virus were then inoculated onto the cell monolayers with $20 \mu \mathrm{g}$ of trypsin per $\mathrm{mL}$ and incubated for 3-5 days at $37^{\circ} \mathrm{C}$ with $5 \% \mathrm{CO}_{2}$. Virus-induced $\mathrm{CPE}$ was observed 
and expressed as TCID50/mL according to the Reed and Muench method.

\section{Viral replication kinetics}

Virus with a multiplicity of infection (MOI) of 0.01 was inoculated onto Vero cell monolayers in T-25 culture flasks with $20 \mu \mathrm{g}$ of trypsin per mL. Viral cultures were harvested at $0,12,24,36,48,60$ and 72 hours postinfection (hpi). The number of viral genome copies was determined by real-time PCR (developed in our lab).

\section{Electron microscopy}

PEDV-infected Vero cells were harvested when more than 90\% of the culture showed CPE. After being frozen and thawed three times, the supernatant and cells were collected and centrifuged at 10,000 rpm for $1 \mathrm{~h}$ and then filtered with a $0.22-\mu \mathrm{m}$-pore-size filter (Merck Millipore, Germany) to remove the cell debris. Subsequently, the supernatant was mixed with polyethylene glycol 8000 (PEG-8000; Solarbio, China) at a $10 \%$ final concentration overnight. After centrifugation at $12,000 \mathrm{rpm}$ and $4{ }^{\circ} \mathrm{C}$ for $2 \mathrm{~h}$, viral particles were resuspended in Tris-buffered saline solution (TBS) and then negatively stained with $2 \%$ phosphotungstic acid and examined using a transmission electron microscope (JEOL, JEM-1200EX, Japan). Virions on infected Vero cell surfaces were imaged according to methods described in a previous study [24].

\section{Immunofluorescence analysis}

Vero cells in 6-well plates were inoculated with $\mathrm{CH} /$ $\mathrm{HBXT} / 2018$ at passage 10 (P10) at an MOI of 0.01 using virus growth medium as a negative control. At $6,12,24$, and $36 \mathrm{~h}$ after inoculation, the medium was removed and cells were washed three times with PBS. The cells were fixed with $4 \%$ paraformaldehyde for $30 \mathrm{~min}$ at $4{ }^{\circ} \mathrm{C}$, and then 1 $\mathrm{mL}$ of penetrant $(0.25 \%$ Triton X-100; Solarbio, China), was added for $10 \mathrm{~min}$ at room temperature. After washing three times with PBS, the cells were blocked with 5\% bovine serum albumin (BSA; Solarbio, China) for $1 \mathrm{~h}$. The plates were reacted with a 1:2,000 dilution of mouse anti-PEDV-N protein MAbs \#12 (prepared and stored in our laboratory) followed by a dilution of Alexa Fluor ${ }^{\circledR} 488$-conjugated goat anti-mouse IgG (Abcam, UK) at $37^{\circ} \mathrm{C}$ for $1 \mathrm{~h}$. Finally, cells were stained with 4',6-diamidino-2-phenylindole (DAPI; Vectorlabs, USA) for $5 \mathrm{~min}$ and washed with PBS. The samples were examined under a fluorescence microscope (Olympus, Japan).

\section{Sequence analysis and phylogenetic tree construction}

Viral RNA was extracted from intestinal contents using an RNeasy Mini Kit (QIAGEN, USA). Reverse transcription and amplification of the PEDV S gene were carried out using AMV reverse transcriptase (Promega, USA) and PrimeSTAR® GXL DNA polymerase (TaKaRa, Dalian, China), respectively, with the primers $5^{\prime}$-GCAACACTATGCATG CCAAT-3' and 5'-TGTTGCACACTTATTGGCAGG-3'. PCR products were isolated by agarose gel electrophoresis and then purified using a DNA Gel Extraction Kit. The target fragment was cloned into the vector included in the TOPO $^{\text {TM }}$ XL-2 Complete PCR Cloning Kit (Invitrogen, USA) and the identity of the plasmids was confirmed by restriction enzyme digestion and sequencing. The sequence was assembled and analyzed using DNAStar 7.0 and BioEdit software, respectively. Forty-eight PEDV reference strains that contained five different PEDV genotypes (Ia, Ib, IIa, IIb and S-INDEL) were obtained from the GenBank database for phylogenetic analysis. A phylogenetic tree was constructed with MEGA6.0 software using the neighbor-joining method with bootstrap values calculated for each node from 1,000 replicates.

\section{Pig infection experiments}

A total of 25 4-day-old conventional suckling piglets were used to determine the virulence and infectious titer (the median pig diarrhea dose, $\mathrm{PDD}_{50}$ ) of the $\mathrm{CH} / \mathrm{HBXT} / 2018$ strain according to a method used in our previous study [25]. In detail, all piglets were randomly divided into four experimental groups (G1-G4) and one mock-infected group (G5) (Table 1). Each piglet was housed in an individual steel cage, and each group of pigs was housed in a different room. Before inoculation, we collected fecal samples from all piglets and tested the umbilical cord blood of sows, using a commercial enzyme-linked immunosorbent assay (ELISA) kit (Biovet, Canada) to ensure that none of the piglets were infected with PEDV. The piglets in groups 1 to 4 were each inoculated orally with $3 \mathrm{~mL}$ of tenfold serially diluted (from $10^{-6}$ to $10^{-9}$ ) P4 CH/HBXT/2018 (4.33 $\log _{10}$ $\mathrm{TCID}_{50} / \mathrm{mL}$ ), and the mock-infected group was inoculated with $3 \mathrm{~mL}$ of PBS. After inoculation, clinical symptoms were observed and scored daily for fecal consistency (scores: $0=$ normal, $1=$ pasty, $2=$ semiliquid, and $3=$ liquid). At the same time, rectal swabs were collected daily to test fecal viral RNA shedding by real-time PCR. Intestinal samples were collected for hematoxylin and eosin (HE) staining and immunohistochemistry (IHC) examination. The $\mathrm{PDD}_{50}$ was determined as the reciprocal of the virus dilution at which $50 \%$ of pigs developed watery diarrhea at a given time point, using the Reed and Muench method. 
Table 1 Summary of pig groups, inoculum and diarrhea outcomes after infection with PEDV in suckling pigs

\begin{tabular}{lllllll}
\hline Pig group & Pig numbers & Inoculum ${ }^{\mathrm{a}}$ & $\begin{array}{l}\text { Calculated inoculum infec- } \\
\text { tious titers }\left(\log _{10} \text { TCID }_{50} /\right. \\
\mathrm{mL})^{\mathrm{c}}\end{array}$ & $\begin{array}{l}\text { Tested inoculum } \\
\text { RNA titers (CT } \\
\text { value })^{\mathrm{d}}\end{array}$ & $\begin{array}{l}\text { Diarrhea (percent) } \\
\text { e }\end{array}$ & $\begin{array}{l}\text { Fecal virus RNA } \\
\text { shedding (CT } \\
\text { value) }\end{array}$ \\
\hline G1 & 5 & $10^{-6}$ diluted P4 & -2.33 & 31.66 & $5 / 5(100)$ & $17.49-26.65$ \\
G2 & 5 & $10^{-7}$ diluted P4 & -3.33 & 31.92 & $5 / 5(100)$ & $19.02-25.00$ \\
G3 & 5 & $10^{-8}$ diluted P4 & -4.33 & 31.36 & $5 / 5(100)$ & $22.27-28.27$ \\
G4 & 5 & $10^{-9}$ diluted P4 & -5.33 & 31.55 & $1 / 5(20)$ & $21.67-35.89$ \\
Mock & 5 & PBS & - & - & $0 / 5(0)$ & $-{ }^{\mathrm{f}}$ \\
\hline
\end{tabular}

${ }^{a}$ All piglets were orally inoculated with $3 \mathrm{~mL}$ of inoculum

${ }^{\mathrm{b}} \mathrm{G} 6-\mathrm{G} 9$ were infected with $\mathrm{P} 4$ cell culture-adapted CH/HBXT/2018

${ }^{\mathrm{c}}$ Titers were calculated based on the titer of the original $\mathrm{P} 4$ virus $\left(10^{4.33} \mathrm{TCID}_{50} / \mathrm{mL}\right)$ and dilution times

${ }^{\mathrm{d}} \mathrm{CT}$ value: the mean cycle threshold value. A critical point was set at 35 ; CT values greater than 35 were considered negative

${ }^{\mathrm{e}} \mathrm{Fecal}$ scores of 3 as determined at 7 DPI for pigs in G6-G9 and the control group

${ }^{\mathrm{f}}$ Negative or below the detection limit of real-time PCR

\section{Histopathology and IHC}

At necropsy, small-intestine tissue specimens were examined and collected from each piglet. After $48 \mathrm{~h}$ of fixation in $4 \%$ paraformaldehyde solution at room temperature, tissue specimens were processed and embedded in paraffin. The paraffin-embedded tissues were cut into thick sections on a microtome (Leica, Germany), deparaffinized with xylene, and washed in decreasing concentrations of ethanol. Then, the intestinal tissue specimens were routinely stained with HE (Baso, China) for histopathology or subjected to IHC using PEDV-N-specific monoclonal antibodies (MAbs) (prepared in our laboratory).
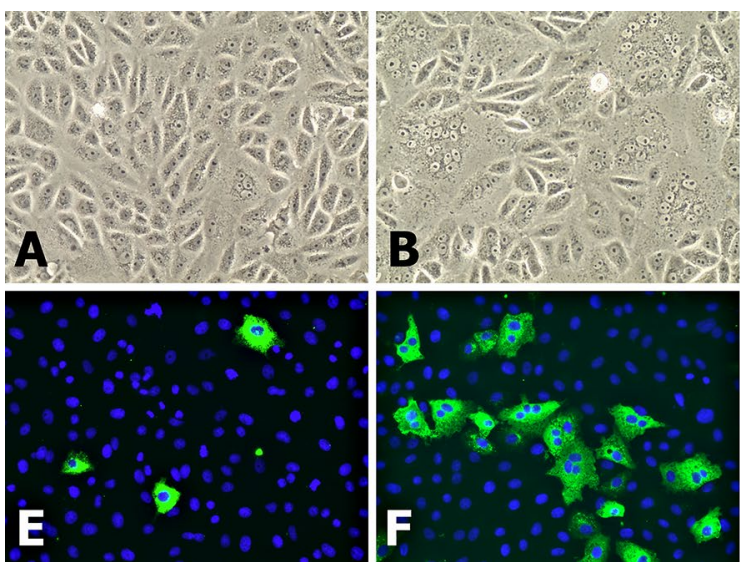

Fig. 1 Isolation and detection of the PEDV CH/HBXT/2018 strain in Vero cells. The upper and lower panels show light and immunofluorescence images, respectively, of Vero cells infected with the PEDV CH/HBXT/2018 strain. (A) Vero cells were seeded in T-25 culture flasks and infected with P5 virus at an MOI of 0.01. CPE was observed at 6 hpi under a microscope $(400 \times)$. (B-D) CPE was

\section{Results}

\section{Biological characterization of the $\mathrm{CH} / \mathrm{HBXT} / 2018$ strain}

Typical PEDV CPE, including cell rounding, syncytial, vacuoles and, eventually, detachment was observed in cells infected with the P3 CH/HBXT/2018 strain. Typical CPE caused by $\mathrm{P} 5$ is shown in comparison to uninoculated cells in Fig. 1. CPE was clearly observed at 6 hpi (Fig. 1B), and more than 95\% CPE was observed at 36 hpi (Fig. 1D). Immunofluorescence assay results indicated that the $\mathrm{CH} /$ HBXT/2018 strain could be detected with PEDV-N-specific

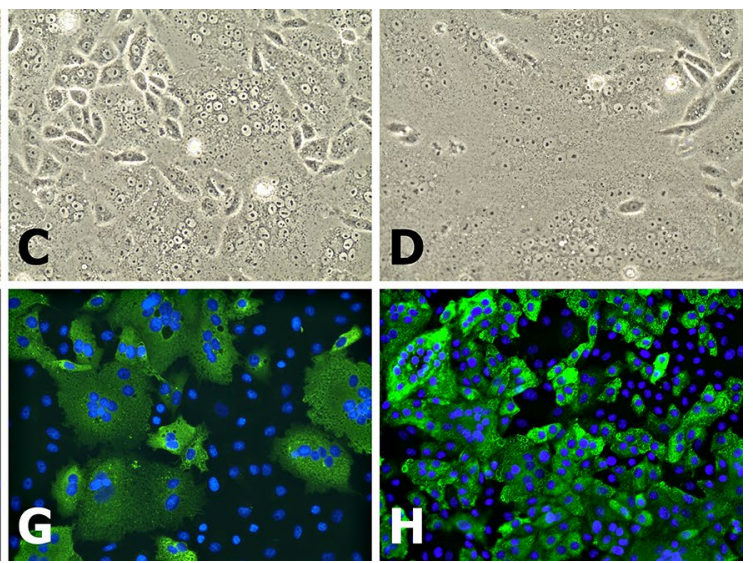

observed at 12, 24 and 36 hpi, respectively. (E) Immunofluorescence assay results for the PEDV CH/HBXT/2018 strain at P10 in infected Vero cells at $6 \mathrm{hpi}(400 \times)$. PEDV antigens and nuclei were detected with mouse anti-PEDV $\mathrm{N}$ protein MAbs and DAPI, respectively; (F-H) green fluorescent signals were observed at 12, 24 and $36 \mathrm{hpi}$, respectively 
MAbs. A small amount of fluorescent signal was detected at 6 hpi for P10 virus at an MOI of 0.01 (Fig. 1E), and the signals gradually increased from 12 to $36 \mathrm{~h}$ (Fig. 1F, G, and H).

The viral replication kinetics of the $\mathrm{CH} / \mathrm{HBXT} / 2018$ strain in Vero cells were examined, and the results showed that the number of viral genome copies continued to increase after inoculation (Fig. 2). The viral titers of the serially passaged PEDV CH/HBXT/2018 strain at P1 and P10 were 4.33 $\log _{10} \mathrm{TCID}_{50} / \mathrm{mL}$ and $5.33 \log _{10} \mathrm{TCID}_{50} / \mathrm{mL}$, respectively.

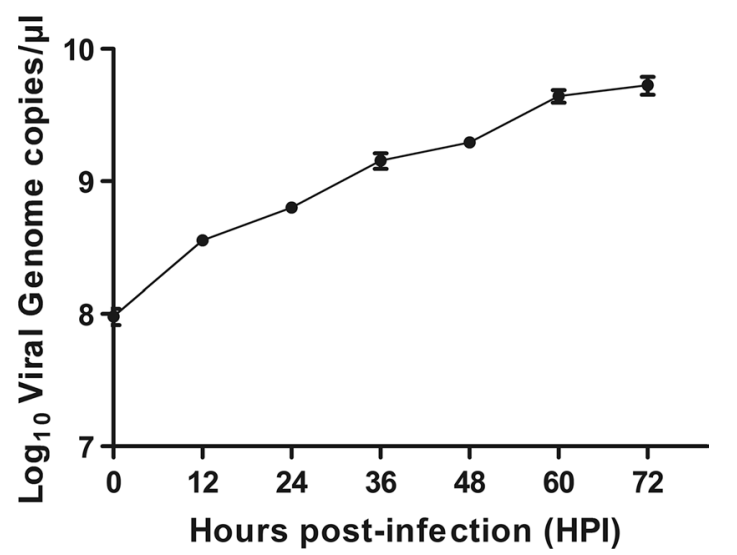

Fig. 2 Viral replication kinetics of the CH/HBXT/2018 strain in Vero cells. Vero cells in T25 flasks were infected with each PEDV isolate at an MOI of 0.01. After incubation at $37{ }^{\circ} \mathrm{C}$ for various time periods, cells and supernatants were harvested, and the number of viral genome copies was determined by real-time PCR
Virions of the CH/HBXT/2018 strain were imaged by electron microscopy (EM), and the results showed that they were typical coronavirus particles approximately $80-120 \mathrm{~nm}$ in diameter with a crown shape (Fig. 3A). These particles were also observed on surface sections of PEDV-infected Vero cells (Fig. 3B).

Sequence analysis of the $\mathrm{S}$ protein showed that compared with classical or attenuated PEDVs, such as the CV777 strain, the CH/HBXT/2018 strain contained novel insertions and deletions. A 4-aa insertion (QGVN) and a 1-aa insertion $(\mathrm{N})$ were found at positions 58-59 and 139-140, respectively, and two deletions were detected at positions 163-164 (a 2-aa deletion of DI) and 1199 (a 1-aa deletion of N). Phylogenetic analysis based on the $\mathrm{S}$ gene indicated that the $\mathrm{CH} / \mathrm{HBXT} / 2018$ strain belonged to genogroup GIIa (Fig. 4), along with other recently isolated PEDV strains from China and the United States.

\section{Determination of the infectious titer and virulence of the $\mathrm{CH} / \mathrm{HBXT} / 2018$ strain}

To determine the infectious titer and virulence of the $\mathrm{CH} /$ HBXT/2018 strain, the $\mathrm{PDD}_{50}$ was determined using 4-dayold conventional suckling pigs. Before inoculation, all piglets were lively, showed no clinical symptoms, and had no PEDV genetic material detected in their fecal samples by PEDV-specific real-time PCR. During the experiment, none of piglets in the negative control group developed diarrhea, and all of their rectal swab samples were negative for PEDV

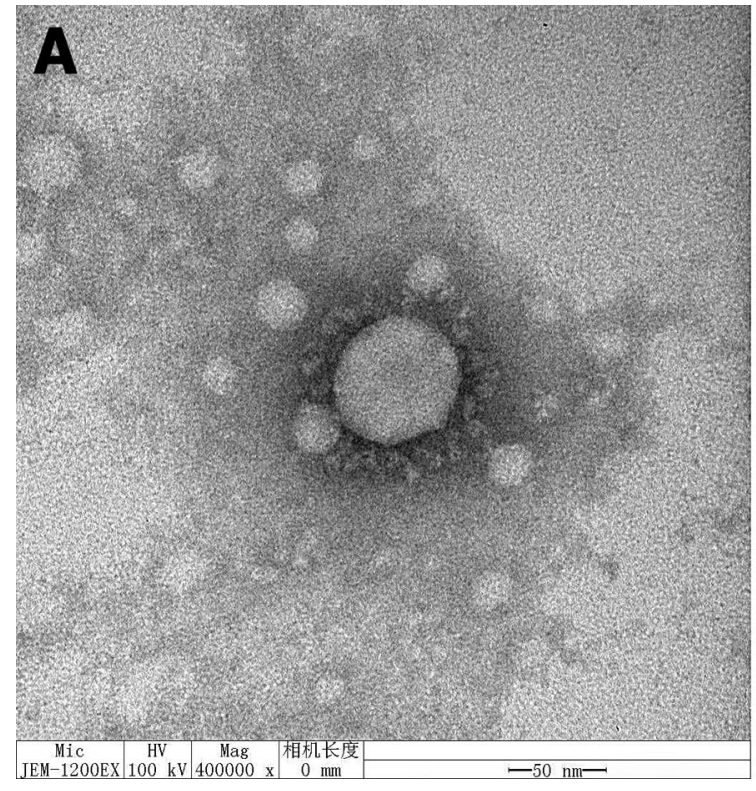

Fig. 3 Virions of the CH/HBXT/2018 strain in cell culture medium from infected Vero cells or on the surface of infected Vero cells were observed by EM. (A) Images of PEDV virions in cell culture medium from Vero cells infected with the PEDV CH/HBXT/2018 strain, as

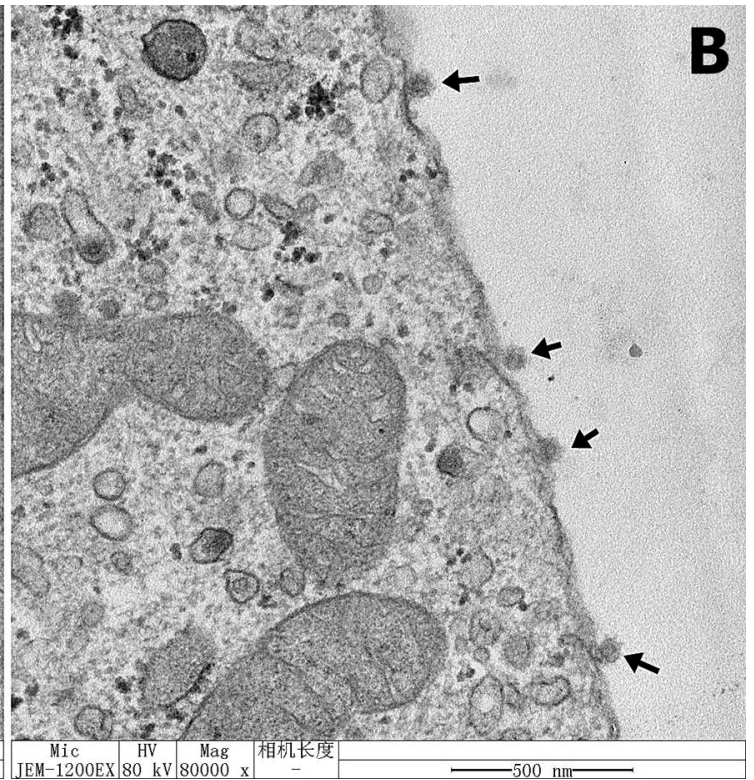

indicated by the arrow. Scale bar $=50 \mathrm{~nm}$. (B) Images of a PEDVinfected Vero cell. PEDV particles (arrowheads) on the surface of an infected Vero cell, as shown by the arrow. Scale bar $=500 \mathrm{~nm}$ 


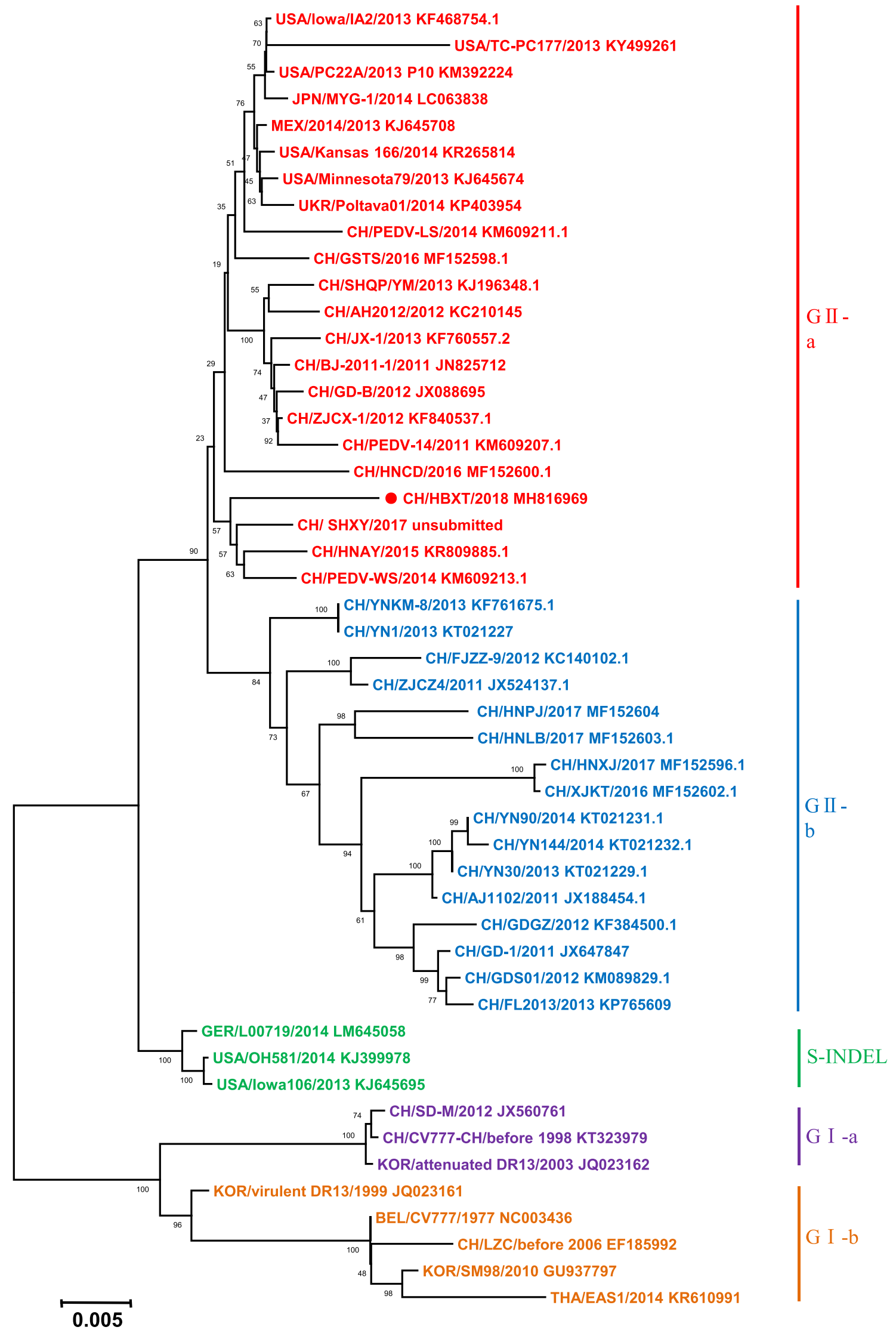


4Fig. 4 Phylogenetic analysis based on the $\mathrm{S}$ gene of the $\mathrm{CH} /$ HBXT/2018 strain. The tree was constructed by the neighbor-joining method, and bootstrap values from 1,000 resamplings are shown for each node

RNA by real-time PCR. After infection, clinical symptoms, including watery diarrhea, vomiting, weight loss and depression, were observed in G6 to G9, while clinical signs and fecal shedding of PEDV RNA were negative in the control group. By 7 days post-inoculation (dpi), viral RNA fecal shedding in samples from rectal swabs or intestinal contents became positive in G1-G4 piglets $\left(10^{-6}-10^{-9}\right.$ diluted virus), with cycle threshold (CT) values ranging from 17.49 to 32.98 (Table 1). In detail, $100 \%$ (5/5) of pigs in G1, G2 and $\mathrm{G} 3$ and $20 \%$ (1/5) of pigs in G4 had diarrhea, and no pigs $(0 / 5)$ in the mock-infected group had diarrhea (Table 1$)$. The cutoff time point was set as $7 \mathrm{dpi}$ for determination of the $\mathrm{PDD}_{50}$, which was $8.63 \log _{10} \mathrm{PDD}_{50} / 3 \mathrm{~mL}$. This value was very different from the $\mathrm{TCID}_{50}$ titer $\left(4.33 \log _{10} \mathrm{TCID}_{50} / \mathrm{mL}\right)$.

All of the diarrheal piglets were anorexic and depressed and displayed weight loss (Fig. 5A). At necropsy, typical macroscopic PED-like lesions were found in the small intestines; the intestinal tract was distended, transparent and filled with yellow fluid, and mesenteric congestion was present (Fig. 5B and C). The results of histopathological examination showed viral enteritis in all diarrheal piglets, including shortening, fusion and sloughing of the small intestinal villi (Fig. 5D and E). The piglets in the control group exhibited normal intestinal histopathology (Fig. 5F). Furthermore, immunohistochemical examination revealed that PEDV antigens were predominant in the cytoplasm of the epithelial cells of atrophied villi in some segments of the small intestines (Fig. 5G and H). No PEDV antigens were present in the small intestines of any piglets in the mock-infected control group (Fig. 5I).

\section{Discussion}

PED was first reported in England in 1971 and then spread to China in 1986 [5]. From 1986 to 2010, PED caused by the classical European strain CV777 was mostly regional and occurred sporadically in China but did not cause significant economic losses to the swine industry [22]. In 2010, a largescale epidemic caused by a PEDV strain with sequences that were distinct from those of CV777 caused outbreaks in China resulting in high morbidity and mortality and serious economic losses [22]. In the past, many commercial vaccines, such as killed/inactivated or attenuated PEDV vaccines based on the classical CV777 strain, were widely used on Chinese pig farms and played an important role in the prevention and control of PED [2]. However, since 2010, new highly virulent PEDV variants characterized by partial insertion and deletion mutations in the $\mathrm{S}$ gene relative to classical strains became prevalent in China. These new highly virulent PEDV variants belong to the GII genogroup and cause 50-100\% mortality. Commercial vaccines based on the classical strain do not provide effective protection against these variants [26]. Therefore, there is an urgent need to develop new vaccines based on current, prevalent, highly virulent PEDV variants. Improved understanding of the biological characteristics and pathogenicity of currently prevalent Chinese PEDV variants is very important for the prevention and control of PED in China. For this purpose, we isolated and passaged a current, prevalent, highly virulent Chinese genotype GIIa PEDV strain, CH/HBXT/2018 (GenBank accession number MH816969), in Vero cells, and we investigated its biological characteristics and pathogenicity.

Phylogenetic analysis based on the $\mathrm{S}$ gene showed that the $\mathrm{CH} / \mathrm{HBXT} / 2018$ strain belongs to genotype GIIa, along with other highly virulent strains isolated in recent years, including the US PC22A strain and Chinese AH2012/12 strain (Fig. 4). Compared to the classical strains CV777 and DR13, the highly virulent PEDV variants of the GII genogroup show insertion, deletion and substitution mutations in the $\mathrm{S}$ gene, suggesting that the increased virulence of PEDV variants is mainly due to mutations in the $S$ gene $[15,25,26]$. Analysis of the $\mathrm{S}$ protein sequence of $\mathrm{CH} / \mathrm{HBXT} / 2018$ showed that it contains typical insertions and deletions that have also been found in other recently isolated highly virulent PEDV variants from China and other countries. The consistency of the $S$ gene sequence between the CH/HBXT/2018 strain and currently, prevalent, highly virulent $\mathrm{PEDV}$ variants suggests that the $\mathrm{CH} /$ HBXT/2018 strain may provide better protection than classical strains against currently, prevalent, highly virulent PEDV variants. However, this hypothesis requires further evaluation.

In previous animal infection studies of highly virulent PEDV variants, such as the PC22A [25], BJ1102C [18] and AH2012/12 strains [27], all strains caused watery diarrhea, dehydration, variable vomiting, and high mortality and morbidity in newborn pigs. In this study, typical PEDV clinical symptoms and intestinal pathological damage were observed in pigs infected with strain $\mathrm{CH} / \mathrm{HBXT} / 2018$, and the $\mathrm{PDD}_{50}$ of the CH/HBXT/2018 strain was determined to be 8.63 $\mathrm{PDD}_{50} / 3 \mathrm{~mL}$ at $7 \mathrm{dpi}$. Compared to the PC22A PEDV strain (7.83 $\log _{10} \mathrm{PDD}_{50} / 3 \mathrm{~mL}, 24 \mathrm{hpi}$ ) [25], the infectious titer of the $\mathrm{CH} / \mathrm{HBXT} / 2018$ strain was higher $\left(8.63 \log _{10} \mathrm{PDD}_{50} / 3\right.$ $\mathrm{mL}, 7 \mathrm{dpi}$ ). These results indicated that the $\mathrm{CH} / \mathrm{HBXT} / 2018$ strain is highly virulent.

\section{Conclusions}

In this study, a highly virulent Chinese genotype GIIa PEDV strain, CH/HBXT/2018, was successfully isolated and serially propagated using Vero cells. The biological 

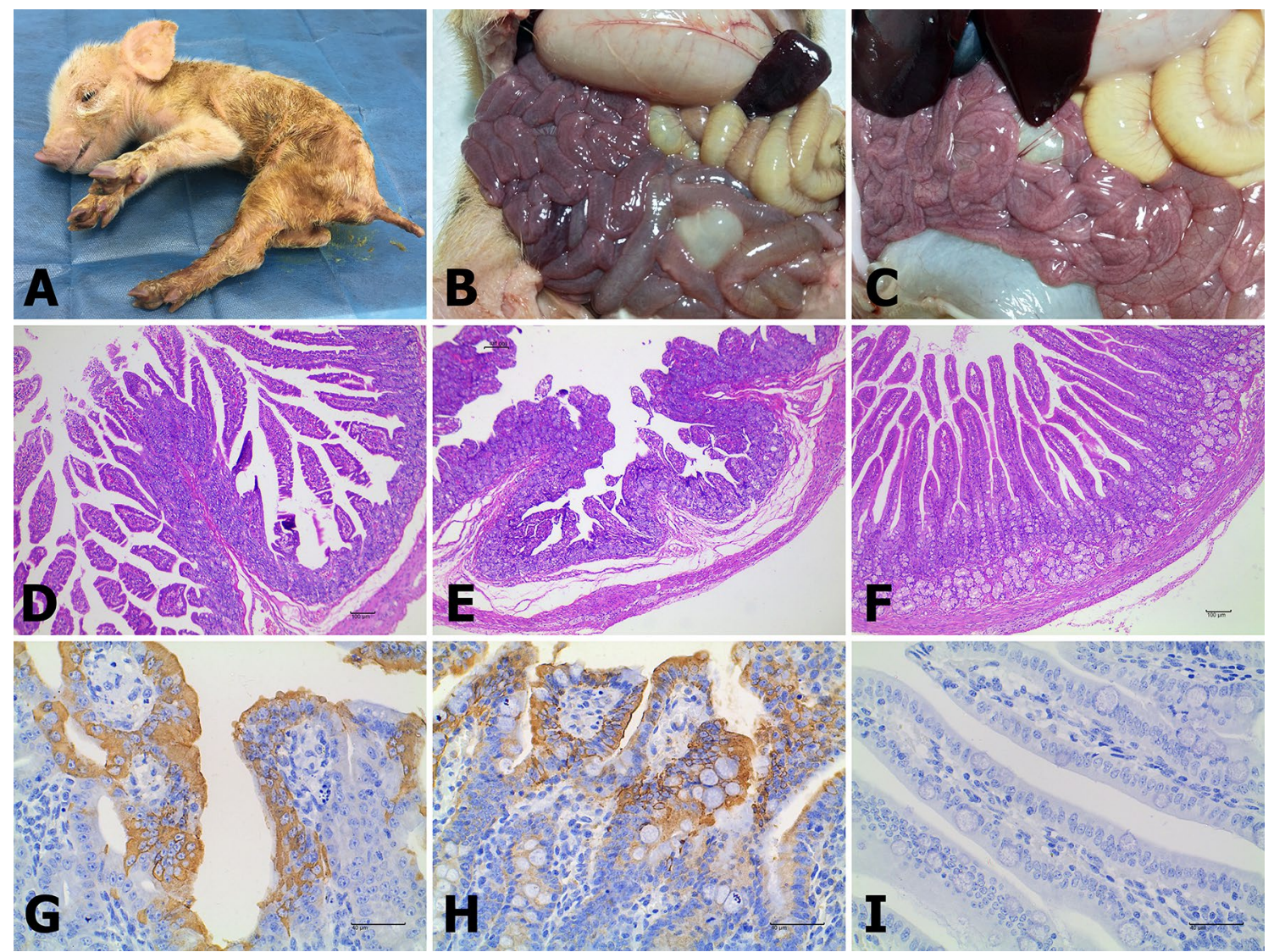

Fig. 5 Clinical symptoms, necropsy examinations, histopathology and IHC of the small intestines of piglets inoculated with P4 of the $\mathrm{CH} / \mathrm{HBXT} / 2018$ strain $\left(10^{4.33} \mathrm{TCID}_{50} / \mathrm{mL}\right)$. (A) The infected pigs were anorexic and depressed and had severe diarrhea. (B-C) Necropsy examinations of $\mathrm{CH} / \mathrm{HBXT} / 2018$-infected piglets. Severe hyperemia, swelling and transparency were present in the intestinal tissues, especially in the small intestines. (D-F) HE-stained tissue sections of jejunum from CH/HBXT/2018-infected and mock control piglets $(100 \times$ magnification). (D) Severe villous abruption was observed in the infected piglets. (E) Severe villous atrophy and fusion, degeneration and necrosis of mucosal epithelial cells were observed in the infected piglets. (F) The normal villous epithelium of the jejunum from mock control piglets. (G-I) Detection of PEDV antigen by IHC analysis of jejunal tissue sections from $\mathrm{CH} /$ HBXT/2018-infected and mock-infected control piglets (400× magnification). (G-H) PEDV antigen signals appear brown and were detected in jejunal epithelial cells from CH/HBXT/2018-infected piglets. (I) No PEDV antigen was detected in jejunum from mockinfected control piglets

\section{Compliance with ethical standards}

characteristics and pathogenicity of the virus were further elucidated. The information provided by this study is useful for future pig challenge studies and the development of new effective vaccines against PEDV in China.

Acknowledgements This study was supported by the National Natural Science Foundation of China (Grant no. 31602095), the National Key Research and Development Program (2016YFD0501505), the China Agriculture Research System (CARS-35) and the Central Public Interest Scientific Institution Basal Research Fund (Y2016CG23).

Author contributions $\mathrm{XL}, \mathrm{YW}$ and $\mathrm{YZ}$ conceived and designed the experiments. XL wrote the manuscript and analyzed the data. XL performed the sample collection. XL, LZ, QZ, PZ, YF, ZD, DZ, WL, and JF performed the experiments. All authors read and approved the final manuscript.
Conflict of interest The authors declare that they have no competing interests.

Ethics approval All piglets used in the present study were humanely bred during the experiment and euthanized at the end of the experiment. Animal care and use protocols were reviewed and approved by the Institutional Animal Use and Care Committee of Lanzhou Veterinary Research Institute. 


\section{References}

1. Guo J, Fang L, Ye X, Chen J, Xu S, Zhu X, Miao Y, Wang D, Xiao $S$ (2018) Evolutionary and genotypic analyses of global porcine epidemic diarrhea virus strains. Transbound Emerg Dis. https:// doi.org/10.1111/tbed.12991

2. Sun D, Wang X, Wei S, Chen J, Feng L (2016) Epidemiology and vaccine of porcine epidemic diarrhea virus in China: a minireview. J Vet Med Sci 78(3):355-363. https://doi.org/10.1292/ jvms.15-0446

3. Pensaert MB, de Bouck P (1978) A new coronavirus-like particle associated with diarrhea in swine. Arch Virol 58(3):243-247

4. Choudhury B, Dastjerdi A, Doyle N, Frossard JP, Steinbach F (2016) From the field to the lab-an European view on the global spread of PEDV. Virus Res 226:40-49. https://doi.org/10.1016/j. virusres.2016.09.003

5. Lin CM, Saif LJ, Marthaler D, Wang Q (2016) Evolution, antigenicity and pathogenicity of global porcine epidemic diarrhea virus strains. Virus Res 226:20-39. https://doi.org/10.1016/j.virus res.2016.05.023

6. Paraguison-Alili R, Domingo CY (2016) Phylogenetic tracking of current porcine epidemic diarrhea virus (PEDV) strains in the Philippines. Arch Virol 161(9):2601-2604. https://doi. org/10.1007/s00705-016-2938-0

7. Pan Y, Tian X, Li W, Zhou Q, Wang D, Bi Y, Chen F, Song $Y$ (2012) Isolation and characterization of a variant porcine epidemic diarrhea virus in China. Virol J 9:195. https://doi. org/10.1186/1743-422X-9-195

8. Park S, Kim S, Song D, Park B (2014) Novel porcine epidemic diarrhea virus variant with large genomic deletion, South Korea. Emerg Infect Dis 20(12):2089-2092. https://doi.org/10.3201/ eid2012.131642

9. Yamamoto R, Soma J, Nakanishi M, Yamaguchi R, Niinuma S (2015) Isolation and experimental inoculation of an S INDEL strain of porcine epidemic diarrhea virus in Japan. Res Vet Sci 103:103-106. https://doi.org/10.1016/j.rvsc.2015.09.024

10. Vui DT, Thanh TL, Tung N, Srijangwad A, Tripipat T, Chuanasa T, Nilubol D (2015) Complete genome characterization of porcine epidemic diarrhea virus in Vietnam. Arch Virol 160(8):19311938. https://doi.org/10.1007/s00705-015-2463-6

11. Puranaveja S, Poolperm P, Lertwatcharasarakul P, Kesdaengsakonwut S, Boonsoongnern A, Urairong K, Kitikoon P, Choojai P, Kedkovid R, Teankum K, Thanawongnuwech R (2009) Chinese-like strain of porcine epidemic diarrhea virus, Thailand. Emerg Infect Dis 15(7):1112-1115. https://doi.org/10.3201/eid15 07.081256

12. Crawford K, Lager KM, Kulshreshtha V, Miller LC, Faaberg KS (2016) Status of vaccines for porcine epidemic diarrhea virus in the United States and Canada. Virus Res 226:108-116. https://doi. org/10.1016/j.virusres.2016.08.005

13. Lara-Romero R, Gomez-Nunez L, Cerriteno-Sanchez JL, Marquez-Valdelamar L, Mendoza-Elvira S, Ramirez-Mendoza H, Rivera-Benitez JF (2018) Molecular characterization of the spike gene of the porcine epidemic diarrhea virus in Mexico, 20132016. Virus Genes 54(2):215-224. https://doi.org/10.1007/s1126 2-017-1528-x

14. Jarvis MC, Lam HC, Zhang Y, Wang L, Hesse RA, Hause BM, Vlasova A, Wang Q, Zhang J, Nelson MI, Murtaugh MP, Marthaler D (2016) Genomic and evolutionary inferences between American and global strains of porcine epidemic diarrhea virus. Prev Vet Med 123:175-184. https://doi.org/10.1016/j.preve tmed.2015.10.020
15. Lawrence PK, Bumgardner E, Bey RF, Stine D, Bumgarner RE (2014) Genome sequences of porcine epidemic diarrhea virus: in vivo and in vitro phenotypes. Genome Announc. https://doi. org/10.1128/genomea.00503-14

16. Zheng FM, Huo JY, Zhao J, Chang HT, Wang XM, Chen L, Wang CQ (2013) Molecular characterization and phylogenetic analysis of porcine epidemic diarrhea virus field strains in central China during 2010-2012 outbreaks. Bing du xue bao Chin J Virol 29(2):197-205

17. Kaewborisuth C, He Q, Jongkaewwattana A (2018) The accessory protein ORF3 contributes to porcine epidemic diarrhea virus replication by direct binding to the spike protein. Viruses. https:// doi.org/10.3390/v10080399

18. Wang D, Ge X, Chen D, Li J, Cai Y, Deng J, Zhou L, Guo X, Han J, Yang H (2018) The S gene is necessary but not sufficient for the virulence of porcine epidemic diarrhea virus novel variant strain BJ2011C. J Virol. https://doi.org/10.1128/jvi.00603-18

19. Shi D, Lv M, Chen J, Shi H, Zhang S, Zhang X, Feng L (2014) Molecular characterizations of subcellular localization signals in the nucleocapsid protein of porcine epidemic diarrhea virus. Viruses 6(3):1253-1273. https://doi.org/10.3390/v6031253

20. Kim SH, Cho BH, Lee KY, Jang YS (2018) N-terminal domain of the spike protein of porcine epidemic diarrhea virus as a new candidate molecule for a mucosal vaccine. Immune Netw 18(3):e21. https://doi.org/10.4110/in.2018.18.e21

21. Jia A, Feng X, Liu Q, Zhou R, Wang G (2014) Complete genome sequence of CHYJ130330, a highly virulent strain of porcine epidemic diarrhea virus in South China. Genome Announc 2(2):e00165-14. https://doi.org/10.1128/genomea.00165-14

22. Li W, Li H, Liu Y, Pan Y, Deng F, Song Y, Tang X, He Q (2012) New variants of porcine epidemic diarrhea virus, China, 2011. Emerg Infect Dis 18(8):1350-1353. https://doi.org/10.3201/eid18 08.120002

23. Zhang Q, Liu X, Fang Y, Zhou P, Wang Y, Zhang Y (2017) Detection and phylogenetic analyses of spike genes in porcine epidemic diarrhea virus strains circulating in China in 2016-2017. Virol J 14(1):194. https://doi.org/10.1186/s12985-017-0860-z

24. Oka T, Saif LJ, Marthaler D, Esseili MA, Meulia T, Lin CM, Vlasova AN, Jung K, Zhang Y, Wang Q (2014) Cell culture isolation and sequence analysis of genetically diverse US porcine epidemic diarrhea virus strains including a novel strain with a large deletion in the spike gene. Vet Microbiol 173(3-4):258-269. https://doi.org/10.1016/j.vetmic.2014.08.012

25. Liu X, Lin CM, Annamalai T, Gao X, Lu Z, Esseili MA, Jung K, El-Tholoth M, Saif LJ, Wang Q (2015) Determination of the infectious titer and virulence of an original US porcine epidemic diarrhea virus PC22A strain. Vet Res 46:109. https://doi.org/10.1186/ s13567-015-0249-1

26. Wang D, Fang L, Xiao S (2016) Porcine epidemic diarrhea in China. Virus Res 226:7-13. https://doi.org/10.1016/j.virus res.2016.05.026

27. Fan B, Yu Z, Pang F, Xu X, Zhang B, Guo R, He K, Li B (2017) Characterization of a pathogenic full-length cDNA clone of a virulent porcine epidemic diarrhea virus strain AH2012/12 in China. Virology 500:50-61. https://doi.org/10.1016/j.virol.2016.10.011

Publisher's Note Springer Nature remains neutral with regard to jurisdictional claims in published maps and institutional affiliations. 